Geopolítica(s) Revista de estudios sobre espacio y poder ISSN: 2172-3958

http://dx.doi.org/10.5209/GEOP.60707

\title{
La irrupción de subjetividades-otras en la teoría de sistemas-mundo: una mirada desde la periferia
}

\author{
Manuela Boatca (2015) Global inequalities beyond Occidentalism. Farnham: Ash- \\ gate., 288 pp. ISBN 978-1-1382-1557-3.
}

¿Cuáles son las consecuencias de que muchas de las premisas aceptadas desde la teoría social crítica acerca de la desigualdad y el conflicto social adolezcan de un marcado sesgo occidentalista, blanco y patriarcal? A partir de esta pregunta y desde una perspectiva relacional de la pléyade de desigualdades existentes a escala global, la autora propone dar la vuelta a los análisis de la desigualdad social desarrollados desde los enfoques weberiano y marxista no sólo para dar cabida a la crítica sistémica feminista y descolonial, sino, en última instancia, para tratar de introducir la agencia en la teoría de sistemas-mundo ${ }^{1}$.

Desde un análisis crítico de las macroteorías de la modernidad y del capitalismo, se invierte la lógica de pensamiento de estas "grandes teorías sociales", recopilando críticas dentro de las propias corrientes de pensamiento ${ }^{2}$ y cuestionando el evolucionismo, el dualismo y la configuración de jerarquías globales a partir de la subordinación a los elementos clave de sus propias perspectivas teóricas ${ }^{3}$ y la "in-

1 No se pretende con ello desconsiderar la opción de tener en cuenta "grandes actores sociales" o actores sistémicos mundiales, como puede verse en importantes ejemplos de la teoría de sistemas-mundo (ver C. ChaseDunn y T. D. Hall: Rise and Demise: Comparing World-Systems. Boulder (Colorado), Westview Press,1997; P. J. Taylor y C. Flint: Geografía política: Economía-mundo, Estado-nación y localidad, Madrid, Trama editorial, 2002; o I. Wallerstein: World-Systems Analysis: An Introduction, Durham, Duke University Press, 2004), sino llamar la atención a una carencia dentro de dicha corriente analítica: la invisibilización o desplazamiento de multitud de agencias sociales y formas de contestación no consideradas por no desarrollarse a escala global.

2 La autora recoge la importancia de modelos históricos mundiales como el de Korzieniewicz y Morgan — basado en comparar instituciones de propiedad privada en países de rentas altas e instituciones extractivas en los países con rentas bajas (p. 117), hace un análisis a largo plazo del sistema-mundo, observando desigualdades entre países en torno al coeficiente de Gini, la necesidad del desarrollo del subdesarrollo y la relación entre estructuras laborales - como crítica al marxismo o las posturas que enfatizan en la ciudadanía como mecanismo igualador aun siendo un eje global de conflictos (pp. 184-198).

3 Evidentemente, las oposiciones son diferentes. En el caso de Marx, se critica el sobredimensionamiento de la plusvalía — sería materia de otro trabajo ver cómo influye realmente en la teoría de sistemas-mundo- o la ausencia del racismo y el sexismo dentro del análisis, mientras que en el caso de Weber se cuestiona la configuración de la "unicidad europea" a partir de la importancia otorgada al racionalismo moderno occidental — similar a Marx pero no restringido exclusivamente al capitalismo- y de la configuración de jerarquías sociales sobre premisas coloniales y racializadas a partir de creencias religiosas de superioridad cristiana (pp. 30-33 y 157-167) 
visibilidad" de ejes esenciales en el análisis histórico de la desigualdad global en el sistema-mundo moderno. Asimismo, lo que a priori podía presumirse como un análisis de las desigualdades globales de un sistema histórico termina siendo también epistemología pura, al emerger un diálogo entre perspectivas analíticas y, en último término, un cuestionamiento del modo en que se ha analizado la evolución de la economía-mundo capitalista desde los centros de producción del conocimiento.

Así, se considera la importancia del trabajo esclavo, el trabajo doméstico y la proletarización en el centro de la economía-mundo capitalista como elementos entrelazados e inseparables en la configuración de la economía-mundo capitalista. A partir de las críticas vertidas desde la teoría feminista sobre el pensamiento marxista y la economía política en general debido a la ausencia del trabajo de las mujeres en el análisis, la autora articula otra "gran teoría" alternativa acerca de las subalteridades esenciales en la consolidación del sistema-mundo moderno a nivel histórico.

En primer lugar, se propone la totalidad del trabajo humano como oposición inherente al capital, no exclusivamente el trabajo asalariado, lo que incluiría el conjunto del trabajo no asalariado y la producción de subsistencia a escala mundial ${ }^{4}$, frente a las perspectivas dominantes hasta el momento, que han supuesto "la subordinación al proletariado como actor clave y una diferenciación de actividades económicas en términos del grado de producción” (p. 63), relegando al trabajo doméstico a la invisibilidad social y a un papel 'pre-capitalista' o no capitalista ${ }^{5}$.

Todo ello habría tenido un efecto doble: por una parte, se habría configurado la "etnicización" de la fuerza de trabajo, al establecerse una "división y clasificación jerárquica al interior de los Estados que ajustan la economía-mundo capitalista a contextos particulares" (p. 69), estableciendo el racismo conforme a una etnicización flexible y el sexismo en torno a la subordinación impuesta por el patriarcado del sistema-mundo moderno, estableciendo la "domestificación" como tendencia determinante de la economía-mundo capitalista. Por otra, la construcción del género devino en semiproletarización, puesto que las unidades domésticas y el trabajo de subsistencia, así como las actividades no remuneradas han supuesto la institucionalización del género como categoría jerárquica y su consideración como algo estático y no sujeto a procesos dinámicos, trascendiendo toda categoría social a

4 Siguiendo múltiples estudios feministas, la autora sostiene que la lógica de la realidad del capitalismo es inversa a la considerada de forma mayoritaria, puesto que el pilar de la economía sería ese trabajo no libre, que constituiría el $90 \%$ del mismo, y no el ideal de trabajo asalariado, que habría constituido una minoría en términos históricos (p. 53). Además de suponer un cambio radical sobre el análisis de sistemas-mundo por su consideración del trabajo, la inclusión de la producción de subsistencia en el conjunto del trabajo humano podría invitar a pensar en la posibilidad de la coexistencia de minisistemas dentro de la propia economía-mundo capitalista - pese al énfasis dado desde la teoría en la imposibilidad de ello- o en que sea el eje que sostiene la estructura económica global (ver L. McDowell: Working Bodies: Interactive Service Employment and Workplace Identities, Oxford, Wiley-Blackwell, 2009).

5 Frente a ello, Boatcã (pp. 63-67) defiende la unidad doméstica como unidad de análisis, recordando que forma parte del "vórtice institucional" del sistema-mundo moderno, no sólo porque garantizan la reproducción social, sino porque son sistemas de reproducción del poder del trabajo y de recursos internos de subsistencia. Además, subraya la necesidad de un análisis transversal de los elementos de las relaciones de poder -interseccionalidad-, en tanto que son consustanciales a la economía-mundo capitalista —y no algo "previo" o atrasado con respecto a la misma-, esenciales en la desigualdad global y en la construcción de las relaciones desiguales de poder como un proceso continuo. 
través de todo tipo de mecanismos sexistas de opresión y sanción social (pp. 72$73)^{6}$. De esta forma, el género emerge como elemento paliativo de las diferencias de renta en el sistema-mundo moderno, además de desplazar tensiones políticas de la esfera pública a la privada. Esta semiproletarización del género sería "un mecanismo mediante los cuales la plusvalía creada en producción no mercantil era apropiada por el capitalismo" (p. 74), como concepto paraguas de desigualdades dentro de las unidades domésticas, y esa agudización de la semiproletarización de la unidad doméstica estaría en consonancia con la acumulación histórica posibilitada por el trabajo esclavo en la periferia y con la proletarización del trabajo como eslabones necesarios de la misma cadena en el circuito de reproducción del capitalismo (p. 74-75).

Sobre las aportaciones de la teoría descolonial, Boatcã pergeña una crítica al "Occidentalismo" como premisa ontológica y argumentación epistemológica de la dominación europea del sistema-mundo moderno.

Desde esta perspectiva, se considera que el capitalismo moderno-colonial se erigió como centralidad constitutiva de la raza a partir de la producción de una diferencia religiosa en Europa, articulada en 1492, que se sumó a la diferencia colonial en las áreas conquistadas ${ }^{7}$. En este sentido, el occidentalismo no se restringe meramente a Europa o al eurocentrismo, sino a un discurso panoccidentalista que habría construido una jerarquía geopolítica bajo su égida. En otras palabras:

Si el racismo es la matriz que permea cada ámbito del imaginario del sistemamundo moderno/colonial, el "Occidentalismo" es la metáfora general alrededor de la cual las diferencias coloniales han sido articuladas y rearticuladas a través de manos cambiantes en la historia del capitalismo [...] y las ideologías cambiantes motivadas por los conflictos imperiales (Mignolo, 2000: 13; cit. en p. 82).

El evolucionismo y el dualismo europeos se vio encarnado en la praxis reproducida sobre los pueblos "sin religión", para los cuales se introdujo una tabla rasa para inducir subjetividad, al tiempo que se construía una estructura jerárquica basada en la racialización y las desigualdades imperiales y coloniales, emergiendo una etnicización de la fuerza de trabajo a escala global, con esclavos africanos, subordinados americanos y trabajadores "libres" europeos. Además, en paralelo al debate sobre la humanidad de los americanos, en Europa hubo otro sobre teología, ciencia y la naturaleza de las mujeres, vertebrándose jerarquías de género desde Europa que fueron proyectadas globalmente. El matrimonio surgió como un mecanismo institucionalizado de control social de las mujeres, mientras que la celebra-

6 La articulación de prácticas discursivas como elementos productores de "esencialidad femenina", mecanismos performativos y reproductivos de la desigualdad sexual ha sido parte nuclear en esa semiproletarización y construcción institucionalizada del género como algo ad aeternum, como puede verse, por ejemplo, en la creación de la figura de "la mujer doméstica" a través de mitos y personajes literarios desde el siglo XVIII (ver N. Armstrong: Deseo y ficción doméstica, Madrid, Cátedra, 1991).

7 Dentro de la articulación de ese discurso occidentalista, se reconoce un papel determinante a las Misiones cristianas por su política de racialización espacial y colonización emprendidas contra lo no cristiano, y que configuraron cartografías que clasificaron al mundo conforme al dogma cristiano y "los hijos de Noé" por encima de Asia y África — configurados como su alteridad-, a diferencia de América, que "se convirtió en la extensión espacio-temporal europea" (p. 87). 
ción de la maternidad, lo doméstico y la familia como ideal social sujeto a un sistema de normas y regulaciones suponían la deslegitimación de toda forma de independencia sexual (p. 90) ${ }^{8}$.

El grado de humanidad o civilización de colectivos racializados y sexualizados, establecido a partir de la conversión de límites espaciales en fronteras temporales, no sólo se expandió con la Ilustración en términos "civilizatorios" de Europa (pp. 95-96), sino que consolidó un Occidentalismo sostenido sobre un imaginario de pasividad de lo femenino y la inexistencia del trabajo doméstico, por un lado, y la separación entre el mundo civilizado y el colonial-esclavo y la Negritud.

Tras el fin de la Guerra Fría, ese monopolio de la definición de Modernidad construido por Europa Occidental como garantía de su expansión colonial e imperial se habría fundido con una geografía moral europea articulada sobre el proyecto de integración de la UE, creando "un discurso civilizatorio que sitúa a la UE en la cima de la jerarquía de valores derivada del legado histórico y su rol político actual sobre los Estados miembros" (p. 214) que sería eje de un proyecto-proceso de europeización reproductor de viejos esencialismos y jerarquías ontológicas sobre sus Otros, comunitarios o independientes de la UE.

De esta forma, se pone de manifiesto cómo Occidentalismo y sexismo-racismo han sido motores inseparables de la creación y consolidación de una Modernidad unitaria, colonial y excluyente que, en términos académicos, ha silenciado además numerosas formas de Otredad y críticas internas a las perspectivas de análisis de la desigualdad global. Además de cuestionar el nacionalismo metodológico, la falacia de la sobre-generalización y el borrado como tendencias execrables de la producción sociológica occidentalista, se reclama que las teorías de sistemas-mundo necesitan profundizar en la deconstrucción del Occidentalismo y en el énfasis a subalteridades eludidas, cuestión innovada por la propia autora a lo largo de todo el relato.

A diferencia de otros estudios sistémico-mundiales en los cuales colonialismo, racismo y patriarcado se han señalado como componentes "adicionales" del capitalismo, Boatcã invierte su importancia dentro de dicho sistema histórico, resaltando la invisibilización de dichos elementos como recurrencias históricas necesarias para la reproducción sistémica y como patrón dominante de la economía-mundo capitalista (pp. 19 y 52-53). Invirtiendo la jerarquía del "vórtice institucional"” de la teoría de sistemas-mundo, la tríada compuesta por sexismo-racismooccidentalismo no sólo emerge como algo consustancial al sistema-mundo moderno, sino que su recuperación por parte de la autora pone de manifiesto la existencia de esas quiebras dentro de la propia academia, así como abre la posibilidad de mirar a través de subjetividades invisibilizadas y, en último término, demuestra

8 La autora da algunos ejemplos de representaciones sobre las mujeres en este sentido: brujería, la Madre Tierra como una figura maternal, la "tierra virgen" o la asimilación entre tropical y erótico son algunas de ellas.

9 Dicho vórtice institucional se establece en la teoría de sistemas-mundo alrededor de cuatro instituciones características de la economía-mundo capitalista (Taylor y Flint, op. cit., p. 28): los Estados, los pueblos, las clases y los hogares o unidades domésticas. Aunque las cuatro son consideradas como estructuras imprescindibles del sistema-mundo moderno, podría afirmarse que ha existido una corriente mayoritaria dentro de la teoría de sistemas-mundo que ha sobredimensionado el rol de los Estados y el conflicto de clase dentro del análisis histórico (ver E. Balibar y I. Wallerstein, Raza, nación y clase, Madrid, IEPALA,1991), y en el caso de la consideración de "los pueblos" se ha hecho desde el sesgo occidentalista cuestionado por la autora. En este sentido, Boatcã trata de aportar una visión desde "otros" pueblos, "otras" clases y, por supuesto, la importancia de las unidades domésticas en la conformación de la economía-mundo capitalista, de la Modernidad y de la producción del conocimiento. 
la pertinencia de introducir la agencia, tanto política como académica, dentro de los procesos históricos estructurales de la teoría de sistemas-mundo.

Pedro Limón López

Facultad de Ciencias Políticas y Sociología,

Universidad Complutense de Madrid

Email: Pedro.limon@pdi.ucm.es 